\title{
Stuart Hall: tributo a um autor que revolucionou as discussões em educação no Brasil
}

\author{
Marisa Vorraber Costa' \\ Maria Lúcia Castagna Wortmann' \\ Rosa Maria Hessel Silveira"
}

'Universidade Luterana do Brasil (ULBRA), Canoas/RS-Brasil "Universidade Federal do Rio Grande do Sul (UFRGS), Porto Alegre/RS-Brasil

\begin{abstract}
Stuart Hall é um gigante intelectual da contemporaneida$d e^{1}$ (Douglas Kellner, contracapa de Rojek, 2003).

O mito de origem dos Estudos Culturais reza que Stuart Hall é seu pai (Liv Sovik- Sovik, 2003, p. 9).

[...] era um herói, um homem negro que superou os limites impostos pelo racismo e foi um dos maiores teóricos culturais de sua geração (Diane Abott apud Butler, 2014, p. A14).

[...] personagem pública apreciada por sua pedagogia e reconhecida por seu carisma, muito ouvido, lido e comentado no mundo inteiro, traduzido em alemão, italiano, espanhol e também em chinês, Stuart Hall encarna uma figura rara no mundo anglo-saxão: aquela do 'intelectual' (Alizart, 2007, p. 11).

O [pensamento] de Hall pode ser considerado como um pensamento sem garantias ${ }^{3}$ (Restrepo; Walsh; Vich, 2010, p. 10).

Ressalta-se que a noção de diáspora figura como central na reflexão de Hall, [sendo] utilizada para mostrar como as identidades culturais se articulam na contemporaneidade. Mas não só seu pensamento traz essa marca, sua própria vivência, seu itinerário, suas posições políticas e intelectuais narram esse encontro entre conjunturas históricas e pessoais (Escosteguy, 2003, p. 65).
\end{abstract}

Em 10 de fevereiro do corrente ano, o mundo perdeu um dos mais sensíveis e engajados intelectuais do pós-guerra - Stuart Hall - falecido na Inglaterra, aos 82 anos, após longa enfermidade. As diversas manifestações a seu respeito, citadas em epígrafe, não têm a ambição de - 
apontando diferentes facetas suas - comporem uma imagem única e completa do autor, como se fossem peças encaixáveis de um quebra-cabeças. Antes, elas buscam mostrar algumas das múltiplas formas como ele foi-é visto e entendido, em especial pelos que atuam nas Ciências Humanas, sem, entretanto, a elas se restringir. Conforme Sovik (2014, s. p.) aponta, em matéria publicada em $O$ Globo na ocasião de sua morte, “[...] talvez Stuart Hall gostasse de saber que falar dele logo depois de sua morte é participar de uma polifonia bakhtiniana, um conjunto de vozes diferentes que falam sobre ele, o que ele fez e disse, o impacto que teve". E é nessa polifonia que este texto se insere.

Alguns traços de sua biografia são bem conhecidos e tem sido bastante consensual - inclusive a partir do próprio testemunho de Hall - a menção ao entrelaçamento entre sua vida e sua obra, ainda que isto não signifique qualquer determinismo biográfico. Jamaicano, integrante da pequena burguesia da colônia caribenha que tinha acesso a uma educação nos moldes britânicos, o próprio Stuart Hall refletiu - como se pode constatar em diversas entrevistas e textos - sobre como a experiência colonial o marcou de maneira ambígua, dentro da própria família e no entorno onde passou sua infância e juventude. Em entrevista concedida a Kuan-Hsingh Chen (2003), constante do livro Da Diáspora, podemos ler seu relato (evidentemente iluminado por toda sua vivência teórica e política posterior) acerca das ambiguidades vividas no seio de sua família jamaicana - inserida de uma forma confortável na estrutura colonial inglesa e desejando para seus filhos uma maior identificação com este mundo branco. Tal identificação, almejada pela família, vai entrar em conflito com as próprias experiências do jovem Stuart Hall, que vai se conscientizando "da contradição da cultura colonial" (p. 412) e nutrindo o desejo de sair daquela situação ambivalente.

Migrando para a Inglaterra aos dezenove anos, onde viveu até o final de seus dias, Hall vivenciou tal mudança como uma experiência desenraizadora, o que, em suas próprias palavras, redundaria no sentimento de deslocamento que, aliás, muito frequentemente acompanha os migrantes em sua vivência diaspórica: o sentido de distanciamento e de estranhamento em relação aos dois espaços (a nação de origem e a nação de acolhimento). E é na entrevista concedida a Kuan-Hsing Chen (2003, p. 415) que Hall sintetiza tal experiência:

\begin{abstract}
Conheço intimamente os dois lugares, mas não pertenço completamente a nenhum deles. E esta é exatamente a experiência diaspórica, longe o suficiente para experimentar o sentimento de exílio e perda, perto o suficiente para entender o enigma de uma 'chegada' sempre adiada.
\end{abstract}

Na Inglaterra, Hall estudará em Oxford, mas cedo se unirá a outros caribenhos migrantes, num intercâmbio que contribuirá para tomadas de posição e discussões relativas à questão colonial e à independência pós-colonial; mas também entra em contato com membros do Partido Comunista e pessoas atuantes na esquerda britânica, desde 
intelectuais até trabalhadores, sem que isso signifique, como ele mesmo esclarece na mesma entrevista, uma adesão ao Partido e uma assunção acrítica das ideias e ações de inspiração marxista. Participou da criação da primeira Nova Esquerda britânica (New Left), tendo sido um de seus membros mais ativos, inclusive como editor de uma revista - Universities and Left Review, por dois anos, ainda que não se sentisse totalmente à vontade nela, na medida em que julgava insuficiente sua experiência junto à classe trabalhadora inglesa e à Inglaterra em geral. Foi nessa época que entrou em contato com Raymond Williams e Edward P. Thompson, também frequentemente celebrados como pais dos Estudos Culturais.

Outro elemento de sua biografia que assume relevância, na perspectiva de seu trabalho posterior, é o fato de ter sido, nesta época, professor de escola secundária frequentada por alunos de classes populares. A partir de contatos no meio em que circulava, Hall foi indicado para dar aulas sobre mídia, cultura e cinema no Chelsea College, da Universidade de Londres, e, em 1964, foi convidado por Richard Hoggart para criar, com o mesmo, o Center for Contemporary Cultural Studies (CCCS) na Universidade de Birmingham, do qual será diretor de 1968 a 1979. Conforme seus biógrafos, Stuart Hall foi a figura mais importante do Centro, coordenando projetos, produzindo artigos, vivenciando momentos de tensão e efervescência intelectual, como podemos ler na entrevista já mencionada, constante do livro Da Diáspora. Após deixar a direção do CCCS, Hall se engajou em um projeto que lhe parecia desafiador - a Open University, onde atuou entre 1979 e 1997, envolvendo-se com a publicação de obras com acento pedagógico, entendendo-se o pedagógico, aqui, como ênfase em um planejamento editorial cuidadoso, que apresentasse diagramação, variedade de textos e qualidade gráfica, tendo em vista propiciar uma leitura fluente e informada. No uso do epíteto pedagógico, não se quer implicar, obviamente, um aligeiramento e descompromisso, mas sim uma especial consideração ao encontro deste leitor implícito com as ideias bastante inovadoras dos Estudos Culturais. Como adiante veremos, algumas dessas obras adquirirão grande importância e repercutirão na formação de pesquisadores brasileiros da área da educação.

Aposentando-se da Open University, em 1997, Stuart Hall não se retirou completamente das lides intelectuais nem abandonou seu perfil de engajamento em ações e atividades que julgasse relevantes. Assim, Gleen Jordan (2014) sublinha a permanência de seu envolvimento, inclusive em instituições, com artistas, em especial os que trabalhavam com fotografia, filmes e mídia digital, além de seu interesse pela música. Face à importância de sua figura como intelectual engajado, e seu papel no campo dos Estudos Culturais e, de maneira alargada, no pensamento contemporâneo, não é de estranhar que sua vida e atuação tenham ensejado a realização de um filme, The Stuart Hall Project, realizado por John Akomfrah e estreado em 2013.

Educação \& Realidade, Porto Alegre, v. 39, n. 2, p. 635-649, abr./jun. 2014. 
Um dos tópicos que têm sido destacados acerca de Stuart Hall é o fato de que, em sua vasta, produtiva e significativa atuação, não se incluem livros de sua autoria. Os que existem são resultantes de compilações de ensaios seus organizadas por outros. Indagado acerca dessa peculiaridade de seu trabalho, esclareceu em uma de suas entrevistas ${ }^{4}$ que escrevia apenas ensaios e não livros, porque quando escrevia não pensava em publicar. Caracterizou seus textos como estratégicos, visando sempre a intervenções em situações concretas e explicou que os ensaios eram publicados em revistas vinculadas a movimentos sociais, culturais ou artísticos e só mais tarde acabavam sendo traduzidos e disseminados a um público mais amplo. Além disso, justificou que sua modalidade de atuação, vinculada aos Estudos Culturais, levava a marca desses estudos, sendo necessariamente não especializada, transdisciplinar, com temas muito variados, que abarcavam questões de arte, política, cultura, educação e tantas outras. E isso, dizia ele, não dá livro.

Sem dúvida, uma das marcas significativas do trabalho de Stuart Hall, recorrentemente salientada em seus depoimentos, assim como nas análises de alguns autores sobre sua produção, advém de sua visão do trabalho intelectual, que ele considerava estar sempre relacionado com o poder. Argumentava que os intelectuais tradicionais alinham-se com o poder enquanto os críticos interrogam-no, testam-no, expõem suas consequências. Sua posição acerca desse assunto está explicitada na seguinte passagem da já mencionada entrevista a Buarque de Hollanda e Sovik:

Não acredito de forma alguma na objetividade do conhecimento. Mas também não acredito que o conhecimento é simplesmente partidário. Não acredito também que o objetivo do conhecimento seja a vitória do 'nosso lado'. Os intelectuais críticos têm que ser melhores intelectuais do que os intelectuais tradicionais. Os tradicionais podem se ligar às instituições estabelecidas, às universidades, ao Estado, à imprensa, às revistas acadêmicas, aos valores estéticos estabelecidos etc. Os intelectuais críticos têm que saber mais, têm que ser mais competentes, seu trabalho tem que resistir melhor a questionamentos. O que significa que têm que testar seu saber, seus argumentos, sua própria posição, para enfrentar as críticas que fatalmente virão e que podem destruir a eficácia de seu trabalho (Hall, 2003, online).

Trata-se, então, de duas formas diferentes de o trabalho intelectual se relacionar com o poder, dizia ele, mas os novos tempos estariam a exigir um trabalho intelectual crítico, resistente e de qualidade, capaz de produzir um conhecimento novo. Hall caracterizava seu próprio trabalho como "teoricamente informado", e nele lançava mão de teorias para realizar análises de conjunturas. "Eu só teorizo sobre casos", dizia. Insistia em não se considerar um “intelectual militante”, mas um ativista desejoso de que seu trabalho fizesse diferença na disposição dos interesses e das forças políticas. Declarava-se, nesta entrevista a Buar- 
que de Hollanda e Sovik, concedida em 2003, visceralmente envolvido no debate da conjuntura mundial em que estariam sendo "suavemente assimiladas" as desigualdades entre o Norte e o Sul, entre o Primeiro e o Terceiro Mundos. Entendia que seu ativismo dependia de seu trabalho intelectual para tornar sua crítica politicamente ativa e, por isso, gritava na televisão e protestava no rádio para não ver esse debate das desigualdades e diferenças simplesmente diluir-se.

Pode-se então afirmar que o trabalho intelectual de Stuart Hall, dentro e fora da academia, distinguiu-se por ser devotado a questões que importam nas vidas das pessoas, e estas, em toda sua "mundanidade", foram tratadas com rigor e "seriedade mortal" pelos Estudos Culturais ${ }^{6}$. Acreditava sobretudo no diálogo, no trabalho cooperativo e no engajamento, pautando-se por uma posição de humildade intelectual, em que a teoria é um conjunto de conhecimentos contestados, localizados e conjunturais, que precisam ser debatidos. Um conhecimento sem garantias.

Talvez decorra das posições assumidas por Hall, nas quais se mesclam constantemente questões acadêmicas a histórias vividas no cotidiano, o considerável número de publicações voltadas ora a reunir, ora a comentar as direções de estudos propiciadas por sua obra, todas elas organizadas antes de sua morte. Destacam-se, entre essas, cinco livros, publicados entre os anos de 1996 e 2010, que têm como título o seu nome - Stuart Hall -, sendo dois deles originalmente em língua inglesa, um em língua portuguesa, outro em espanhol e, outro, ainda, em francês.

Em Stuart Hall, Critical Dialogues in Cultural Studies, David Morley e Kuan-Hsing Chen (1996) intercalam textos e entrevistas de Hall com considerações feitas por destacados culturalistas sobre temas centrais na obra do autor - tais como ideologia, marxismo e pós-marxismo, pós-modernismo, políticas de internacionalização e questões diaspóricas em raça, etnia e identidade. Já em Stuart Hall, Chris Rojek (2003) analisa de forma instigante um conjunto de ensaios de Hall, destacando ser o criticismo uma das características mais marcantes de seu pensamento, que foi, segundo esse analista, constantemente fertilizado por sua ousada utilização de cruzamentos entre diferentes tradições de pesquisa - marxismo, pós-estruturalismo, feminismo, desconstrucionismo, lacanismo, semiótica, teoria do discurso e pós-modernismo. Como Rojek (2003, p. 16) assinalou, as análises conduzidas por Hall envolvem "uma fusão narrativa sincrética" que poucas vezes resulta em coesão intelectual, e que se situa na articulação de inspirações advindas de Marx, Gramsci, Althusser, Volosinov-Bakhtin, Lacan, Derrida, Foucault, Laclau e Mouffe.

Disso decorre, pelo menos em parte, a qualificação de seu pensamento como "sem garantias", tal como Rojek (2003, p. 16), mas também Eduardo Restrepo, Catherine Walsh e Victor Vich (2010) assinalaram na coletânea intitulada Stuart Hall. Sin garantias, que organizaram a partir da tradução para o espanhol de 26 ensaios por ele escritos. Como salien-

Educação \& Realidade, Porto Alegre, v. 39, n. 2, p. 635-649, abr./jun. 2014.

Disponível em: <http://www.ufrgs.br/edu_realidade> 
Stuart Hall

taram esses comentadores (2010), a obra de Hall está estruturada em um pensamento destinado a revelar o funcionamento do poder e das lógicas da hegemonia, que passa longe da intenção de construir um lugar seguro para localizar seja a cultura popular, sejam as subalternidades racializadas, que foram por ele sempre tomadas como objeto de problematização. No pensamento de Hall, segundo os mesmos comentadores (2010), a teoria precisa dar conta da complexidade das conjunturas para gerar intervenções políticas, não sendo vista, no entanto, organicamente estruturada em princípios que possam encerrar a realidade. Assim, Hall é por eles descrito como um autor que questiona fundamentos teóricos - o já referido criticismo tão presente em sua obra - que procurou, no entanto, reconstruir a partir das mudanças que observava no mundo contemporâneo.

Ao destacarem a importância da obra de Hall, Restrepo, Walsh e Vich (2010) consideram que seus ensaios permitem complexificar os modos de pensar a América Latina a partir de alguns postulados básicos: a crítica ao eurocentrismo, a radical opção transdisciplinar, a postura desconstrutivista, a aposta em um pensamento complexo e a inexistência de garantias para se lidar com o que sucede no mundo (2010, p. 13-14). Também no Brasil, há uma obra que se poderia considerar de caráter antológico sobre este autor. Esta foi organizada por Liv Sovik, em 2003, sob o título Da diáspora. Identidades e mediações Culturais. Stuart Hall, e reúne traduções de 14 textos clássicos do autor inseridos em quatro capítulos que focalizam: Controvérsias; Marcos para os Estudos Culturais; Cultura popular e Identidade; Teoria da recepção, e a transcrição de uma entrevista concedida a Kuan-Hsing Chen, que apresenta o autor por ele próprio.

Já o livro em língua francesa, organizado por Mark Alizart, Éric Macé e Éric Maigret, publicado em 2007, tem como texto principal uma entrevista concedida por Stuart Hall em 2005, por ocasião da exposição Africa Remix, no Centro Georges Pompidou em Paris; além dessa entrevista, compõem o volume uma biografia intelectual de Hall, assim como uma pequena bibliografia selecionada e comentada do autor e uma bibliografia completa do mesmo. É interessante apontar que uma das preocupações maiores dos organizadores foi debater o motivo pelo qual, apesar de sua grande influência no pensamento contemporâneo, a obra de Stuart Hall fosse tão pouco conhecida na França.

É importante registrar ainda (e alguns depoimentos dentre os adiante citados fazem referência a tal fato) que, anteriormente à publicação de Da Diáspora (2003), textos de Stuart Hall circularam no Programa de Pós-graduação em Educação da Universidade Federal do Rio Grande do Sul (PPGEDU/UFRGS), em traduções de capítulos de livros da conhecida série Culture, Media and Identities, publicada na Inglaterra pela editora Sage em associação com a Open University, que teve grande participação de Hall, conforme mencionamos. A série era parte do curso com o mesmo nome e composta por seis livros que focaliza- 
vam, cada um deles, uma das etapas do chamado circuito da cultura, exposto no primeiro volume, intitulado Doing Cultural Studies: The story of the Sony Walkman, editado por Paul Du Gay (1997). Aliás, os primeiros textos de Hall traduzidos e publicados no Brasil (Identidade Cultural na Pós-modernidade ${ }^{7}$ e A Centralidade da Cultura: notas sobre as revoluções culturais do nosso tempo ${ }^{8}$ ) provinham de publicações dos cursos da Open University. Sua tradução e publicação em nosso meio expressava um esforço de professores e alunos do PPGEDU/UFRGS para facilitar o acesso a textos seminais dos Estudos Culturais, que acabaram sendo um marco na introdução e consolidação de tais estudos, tanto neste Programa como em outros de universidades brasileiras. Ao final da década de 1990, a influência do pensamento de Hall foi decisiva para a criação, no Brasil, da primeira linha de pesquisa voltada aos Estudos Culturais em um Programa de Pós-Graduação em Educação.

Não se pode deixar de destacar que foi Tomaz Tadeu da Silva, no campo da Educação, já no início dos anos 1990, o desbravador desse universo dos Estudos Culturais e quem trouxe os primeiros livros em inglês da Open University para o Brasil, dedicando-se a seu estudo e tradução, junto com seus alunos em seminários da pós-graduação. As ideias e peculiaridades do trabalho de Stuart Hall chegaram até nós resultantes do minucioso garimpo realizado por Tomaz Tadeu em busca de novas perspectivas de pensamento para análise da educação brasileira.

\section{Disseminação das Ideias de Hall no Campo da Educação no Brasil}

A entrada, nos anos 1990, dos Estudos Culturais no campo da pesquisa em educação no Brasil, em que as contribuições de Stuart Hall despontam como marco no advento de novas possibilidades de interpretação e entendimento de questões da área, produziu uma visível ebulição intelectual. Professores e pesquisadores de vários estados brasileiros começaram a procurar o Programa de Pós-Graduação em Educação da UFRGS para realizar seus estudos de mestrado e doutorado, atraídos, entre outros motivos, pelas possibilidades teóricas, analíticas e metodológicas aportadas com a nova abordagem que chegava até nós. Alguns desses professores e pesquisadores implicados em tal abordagem, e convidados por nós a comentarem suas experiências nesse sentido, referem suas repercussões em seu trabalho e também em suas vidas. A seguir, trazemos, a partir de suas próprias vozes, algumas facetas desse acontecimento, como nomeia Marlucy Paraíso, hoje professora da Universidade Federal de Minas Gerais (UFMG).

Paraíso menciona ter presentes ainda hoje as sensações do momento em que entrou em contato com os trabalhos de Hall: “[...] descobertas, conexões, aumento de potência e um sentimento de que algo muito novo e cheio de possibilidades acabava de dar sua entrada na educação" (Paraíso, 2014, depoimento). Sensações que, em suas pala-

Educação \& Realidade, Porto Alegre, v. 39, n. 2, p. 635-649, abr./jun. 2014.641 Disponível em: <http://www.ufrgs.br/edu_realidade> 
vras, “[...] deixaram suas marcas nos modos como me constituí como docente, pesquisadora e orientadora na UFMG”. Afirma ter encontrado, na teorização de Hall, “[...] coragem para estudar na educação e no campo do currículo o que naquela época não pareciam projetos sérios e cabíveis na educação: novelas televisivas, notícias de TV, campanhas publicitárias, gibis, filmes, desenhos animados, músicas” (Paraíso, 2014, depoimento). O mesmo ainda acontece hoje, segundo afirma, com seus orientandos, que sublinham ser a leitura de Hall que lhes dá "coragem teórica e política” para a discussão desses temas na educação. Para Paraíso, Hall foi como uma "verdadeira corrente de ar fresco" nos estudos e pesquisas curriculares, assim como em seu próprio modo de ensinar e pesquisar.

Já para Iara Bonin, outra pesquisadora que atravessou fronteiras geográficas e atua no Programa de Pós-Graduação em Educação da Universidade Luterana do Brasil, no Rio Grande do Sul, a leitura de Hall lhe ofereceu importantes referências “[...] não ao estilo de âncoras lançadas para fixar, e sim ao estilo das rajadas de vento - que foram revolvendo e sacudindo a 'poeira' do meu pensamento e me constituíram como pesquisadora”. Bonin sublinha que "[...] a alegria, o desconforto e, sobretudo, a produtividade de meu 'encontro' com Stuart Hall têm sido compartilhados com cada novo grupo de alunos que ingressa no Mestrado, e com cada novo orientando" (Bonin, 2014, depoimento).

Professor e pesquisador que atua na Universidade Federal de Santa Catarina (UFSC), Leandro Belinaso Guimarães também vivenciou essa ebulição dos anos noventa no PPGEDU/UFRGS. Seu primeiro contato com o pensamento de Hall teria desencadeado, segundo ele, "[...] um movimento antropofágico de deglutição de conceitos, modos de escrever e pesquisar, no qual passamos a ver nossas próprias questões investigativas, nossos contextos, com outros olhos" (Guimarães, 2014, depoimento). Guimarães buscou as marcas dos seus gestos de leitura da época e nos relata algumas das suas anotações nas margens de dois dos seus ensaios preferidos de Hall - Estudos Culturais: dois paradigmas e Estudos Culturais e seu legado teórico-, ambos do livro Da Diáspora. Tais anotações evidenciam as repercussões inusitadas dos textos sobre suas formas de pensar. Às margens do primeiro, escreveu: "é interessante ver como o foco de Hall está nas relações”; "ele [Hall] foge de uma abordagem de causas e efeitos”; “a cultura passa a ser ordinária”. Já nas páginas do segundo, encontrou, manuscritos: "há uma recusa das metanarrativas"; "o projeto dos estudos culturais está aberto ao desconhecido, há uma vontade de conectar-se e há um envolvimento com as escolhas que se faz"; "é incrível essa ideia de que a teoria que vale a pena reter é aquela que temos que contestar e não a que falamos com fluência"; "o que gostaríamos de interromper em nós?"; "algo sempre nos escapa...”. O que se pode vislumbrar nestas frases e expressões provocadas pela leitura são sentimentos e, mesmo, reações emocionais desencadeados pelas ideias de Hall, ultrapassando questões de cunho puramente teórico e intelectivo. Guimarães assinala também que os “[...] textos de Hall 
foram importantes não apenas para meus trabalhos de pesquisa, mas com a formação inicial e continuada de professores de ciências e de biologia", o que, a um leitor desavisado, poderia ser uma extrapolação de sua leitura. Entretanto, ele justifica sua asserção, evocando que, através dos textos do autor, ele pode acionar “[...] um entendimento das práticas culturais que ampliava, quase infinitamente, as possibilidades articulatórias a partir das temáticas, até então, vistas como 'próprias' à biologia e ao seu ensino" (Guimarães, 2014, depoimento).

Salientando as contribuições de Hall para os estudos de currículo, campo ao qual tem se dedicado, Paraíso destaca que a introdução das discussões culturais de Stuart Hall no campo do currículo "[...] aqueceu o pensamento curricular e [...] modificou seus temas de estudo, ao trazer outras problematizações e interrogações para a área", o que teria afetado radicalmente a teoria e a pesquisa no campo curricular, de tal forma que quase não se conseguiria mais falar de currículo sem falar de cultura nos estudos do campo. Aliás, o curriculista Antônio Flávio Barbosa Moreira, atualmente professor da Universidade Católica de Petrópolis (UCP), no Rio de Janeiro, ressalta que "[...] os pontos de vista de Stuart Hall sobre a centralidade da cultura contribuíram para o enriquecimento dos estudos curriculares ao estimularem os pesquisadores a articular o foco na cultura com a consideração de fatores econômicos e políticos que, mais recentemente, têm sido menosprezados" (Moreira, 2014, depoimento). Em seu depoimento, Moreira considera que tal noção, enunciada por Hall, pode levar à revisão de alguns equívocos derivados do que ele denominou de "a onda culturalista", a qual, segundo ele, trouxe significativas contribuições, mas, também, problemas, aos estudos de currículo9. E o esclarecimento que ele enfatiza ter essa noção lhe propiciado deriva do alerta de Hall contra a "perspectiva apocalíptica" de entender que "tudo é cultura"; Moreira estende tal alerta às análises dos processos curriculares que focalizam o conhecimento escolar, fortemente marcadas ao longo dos tempos pelas teorias curriculares, para afirmar que, também nas discussões curriculares, "nem tudo é cultura" (Moreira, 2014, depoimento).

Outros conceitos e questões explorados por Hall, assim como características de sua elaboração teórica e escrita, foram relembrados pelos depoentes. Assim, Paraíso ainda salientou que o modo como Hall se indagou e explorou certos conceitos, tais como o de identidade - "[...] fornecendo subsídios e argumentos que se valem de uma variedade de tradições de pensamentos em circulação na sociedade contemporânea, que ele se esforçou para articular, costurar e incorporar" - lhe ensinou "[...] o valor e a importância de construir um discurso não-sectário e que não despreze as importantes contribuições dos diferentes pensamentos sobre o social, o cultural e o político" (Paraíso, 2014, depoimento).

Na mesma direção de reconhecimento das problematizações relativas às identidades-diferenças, mas em articulação com seus estudos específicos, Bonin salienta: 
[...] uma das marcas mais expressivas de meu 'encontro' com a proposta teórica de Stuart Hall foi a possibilidade de me afastar das noções de pureza e de autenticidade comumente acionadas para falar das culturas indígenas. Aprendi a colocar 'sob rasura' algumas representações que fixam e essencializam as identidades/diferenças, ou, em termos mais específicos, fui provocada a estranhar a ideia de que as identidades indígenas seriam constituídas no tecido coeso de suas tradições ancestrais, passando a prestar atenção também às mesclas, às práticas culturais de fronteira e aos movimentos diaspóricos que desestabilizam esses 'tecidos' supostamente coesos (Bonin, 2014, depoimento).

Bonin enfatiza, ainda, que aprendeu com Hall "[...] a levar a efeito a contundente crítica ao eurocentrismo - perspectiva a partir da qual são narradas as histórias e são alicerçadas as memórias sobre os 'outros', os povos indígenas, os sujeitos com os quais venho dialogando há décadas". Também com estudos que abordam as narrativas sobre povos indígenas na Amazônia, José Vicente de Souza Aguiar, professor da Universidade do Estado do Amazonas, nos traz reflexões sobre como as ideias de Stuart Hall motivaram inflexões em seu trabalho. Afirma ele:

Hall colaborou substancialmente para a constituição de um pensar que considera as ideias de movimento, do não fixo, do deslocamento como elementos essenciais que necessitam ser considerados nos Estudos Culturais, sejam eles realizados em regiões relacionadas diretamente aos grandes centros urbanos, sejam em regiões imaginadas em estado de isolamento das chamadas influências culturais das grandes cidades (Aguiar, 2014, depoimento).

Ao identificar o que julga ser a inspiração mais importante trazida pela leitura de Stuart Hall para o campo da educação, Aguiar destaca o "[...] entrelaçamento dos elementos culturais na vida humana, como elementos que subsidiam as suas formas de ser, de viver e de pensar, ao mesmo tempo em que atuam orientando suas disputas na vida social". Neste sentido e se voltando mais especificamente para o âmbito escolar, o pesquisador julga que as pesquisas do campo necessitariam “[...] considerar esta perspectiva de cultura apresentada por Hall, de modo a entender os alunos e suas aspirações, que são criadas no seu tempo e não no tempo de quem planeja e executa os ensinamentos" (Aguiar, 2014, depoimento). João de Deus dos Santos, professor e pesquisador da Universidade do Estado de Mato Grosso (UNEMAT), também aponta possíveis repercussões do pensamento de Hall para pensar as identidades dos alunos que frequentam as escolas. Afirma ele que “[...] tomando-se a identidade sob o enfoque cultural, pode-se notar um amplo leque de questionamentos que se pode fazer sobre como se constituem os sujeitos da educação escolarizada" (Santos, 2014, depoimento); entretanto, observa Santos, “[...] deve-se levar em consideração o intenso processo de interpelação cultural a que todos estão expostos, cotidianamente, dentro ou fora da escola". E dentro das peculiaridades do mundo contemporâneo, "[...] a problematização do papel da escola na formação das identidades ganha novos contornos e novas cores. As- 
sim, já não é mais possível aceitar tranquila e passivamente a resposta moderna da formação do sujeito monolítico, concluso e fixo" (Santos, 2014, depoimento).

Também focalizando as contribuições do pensamento de Stuart Hall para a problematização dos “sujeitos da educação”, Mariangela Momo, professora da Universidade Federal do Rio Grande do Norte (UFRN), inicia seu depoimento destacando a forma como o pensamento de Stuart Hall possibilita problematizar o entendimento da "infância e das crianças, usualmente explicado por meio das teorias da área da Psicologia", desafiando o pesquisador e a pesquisadora a “[...] ver as crianças que estão em nossas escolas hoje por meio de aspectos culturais e entender que a cultura na qual estão inseridas constitui suas identidades, suas formas de ser, de agir e de pensar" (Momo, 2014, depoimento). E não é apenas nesta direção que suas ideias colaboram, afirma a pesquisadora, já que elas também têm ajudado a “[...] entender e a analisar aspectos da cultura na qual as crianças estão inseridas”, com especial ênfase à análise de práticas de consumo. As discussões de Hall sobre a globalização das ofertas culturais, que acentuam, entretanto, o fato de que essa "revolução cultural global não é tão uniforme", mas "[...] é distribuída mundialmente de uma forma irregular e é provável a produção de novas identificações globais e novas identificações locais" (Momo, 2014, depoimento), também instigam sua atividade de pesquisa no campo da Educação.

Observe-se que, em harmonia com algumas observações de outros depoentes, Momo realça a contribuição de Hall para o desenvolvimento de "determinados procedimentos teórico-metodológicos das pesquisas" que tem realizado. Assim, afirma a autora, ela tem procurado "lidar com a multiplicidade de significados", fugindo às oposições binárias mencionadas várias vezes por Hall, ainda que compreenda que sempre, de alguma forma, se está "selecionando e produzindo significados preferenciais” (Momo, 2014, depoimento), conforme o autor discutiu e apontou em vários de seus trabalhos.

\section{Considerações Finais sobre a Relevância da Obra de Hall}

Ao mencionarmos, no início da seção anterior, a ebulição intelectual ocorrida com a entrada dos Estudos Culturais no campo da educação brasileira, com destaque maior para Stuart Hall, deixamos em aberto - para que fosse alimentado pelas vozes dos depoentes convidados - qual seria o seu caráter: se de efemeridade, se de inserção e acomodação no já dito, se de substituição do discurso pedagógico dominante etc. De certa forma, hoje percebemos que não foi nem trivial nem inócua essa movimentação iniciada há mais de vinte anos. Pelo contrário, nossas vivências, acrescidas dos depoimentos a que recorremos (que poderiam ser numericamente bastante expandidos não fosse a urgência de escrevermos este tributo a Hall logo após seu falecimento), apontam

Educação \& Realidade, Porto Alegre, v. 39, n. 2, p. 635-649, abr./jun. 2014. 
que ela foi forte, profunda, marcou indelevelmente uma geração de pesquisadores, expandiu-se territorialmente, revirou concepções e práticas e continua a produzir efeitos em direções variadas e impensadas. Enfim, não se tratou de mais um modismo em uma era em que se muda de posição, identidade, opinião e ideário assim como se troca de roupa.

Nesse sentido, valemo-nos mais uma vez da polifonia bakhtiniana para fechar este tributo, destacando algumas das diferentes formas com que os professores/pesquisadores concluíram ou sintetizaram seus depoimentos:

Uma abordagem que mudou meu modo de compreender, pesquisar e ensinar sobre o currículo e a educação (Paraíso, 2014, depoimento).

Penso que o pensamento de Stuart Hall é amplo, complexo e profícuo para a área da educação e minha intenção foi apenas pontuar três aspectos dentre muitos outros possíveis (Momo, 2014, depoimento)

Busco movimentar essa 'herança', fazer jus ao legado, provocando meus orientandos a pensar com Stuart Hall (Sovik, 2003, p. 217), 'não a teoria como vontade de verdade, mas a teoria como um conjunto de conhecimentos contestados, localizados e conjunturais, que têm que ser debatidos' (Bonin, 2014, depoimento).

É aqui [na referência a cultura nos estudos de currículo] que [...] se destaca a rica contribuição dos estudos de Stuart Hall, importantes para nos ajudarem a tirar melhor proveito das análises centradas na cultura e para minorar problemas presentes nessas análises (Moreira, 2014, depoimento).

A consideração desse legado [de Hall] abre um imenso mosaico de possibilidades de formulação, de problematização e de análise de questões que, aparentemente, estariam resolvidas com o recurso a categorias modernas tradicionais, com a aplicação de métodos já em inúmeras teses, e com o uso de saberes linearmente formalizados em quarentenas cientificistas (Santos, 2014, depoimento).

Hall colaborou não apenas no sentido de preparar nossos olhares para entender as questões culturais e identitárias com as quais desenvolvemos nossas leituras e pesquisas, mas para que seja possível assimilar e internalizar também o pensamento de que as ideias de movimento e deslocamento necessitam também ocorrer naquele que se propõe estudar os fenômenos culturais e identitários. Ou seja, não se trata apenas de um gesto pensado e aplicado de maneira externalizada, mas de uma atitude de internalização no pensamento de quem pratica os estudos culturais (Aguiar, 2014, depoimento).

O que parece não escapar é a atualidade, a pertinência política, os efeitos em nós e nas práticas que nos enredam dos textos de um dos autores mais instigantes e desafiadores do final do século XX: Stuart Hall (Guimarães, 2014, depoimento).

De maneira um pouco provocativa, juntamos a essas sínteses um interessante e arguto vaticínio proferido por Hall, ainda nos anos 1990: “[...] a capacidade de viver com a diferença será [...] o assunto chave do século XXI" (Hall, 1993 apud Restrepo; Walsh; Vich, 2010, p. 361). 
Ora, mesmo um superficial recorrido às intrincadas e complexas lutas empreendidas por diversos grupos na direção do direito de viver as diferenças, em curso nas sociedades contemporâneas, nos conduz a pensar sobre a propriedade desse seu prognóstico. Ressaltamos, no entanto, que isso não implica estarmos atribuindo ao pensamento de Hall qualquer nível de abrangente certeza. Tampouco implica estarmos idealizando as possibilidades explicativas contidas nas reflexões por ele conduzidas, ao longo de sua extensa e intensa atividade de labuta na cultura, sobre um considerável número de temáticas e de conceitos, muitos dos quais colocou sob rasura para poder continuar a utilizar. Como muitos dos depoimentos aqui referidos sublinharam, as teorizações invocadas por Hall não colocam qualquer tema ou problemática em uma zona de conforto; ao contrário, o que caracteriza seu pensamento é a ausência de qualquer garantia para o encontro de explicações totalizadoras. Afinal, não seria isso mesmo o que se poderia esperar de reflexões que se organizam sobre estudos qualificados de impuros, marginais, subalternos e sem garantias? ${ }^{10}$.

Recebido em 05 de março de 2014 Aprovado em 20 de março de 2014

\section{Notas}

1 No original: "Stuart Hall is an intellectual giant of the contemporary era".

2 No original: "[...] personnage public apprécié pour sa pédagogie et reconnu pour son charisme, très écouté, lu et commenté dans le monde entire, traduit en allemande, en italien, en espagnol, mais aussi en chinois, Stuart Hall incarne une figure rare dans le monde anglo-saxon, celle de 'lintelectuel'".

3 No original: "[...] El de Hall puede considerarse como un pensamiento 'sin garantías".

4 Entrevista concedida a Heloisa Buarque de Hollanda e Liv Sovik no ano de 2003; ver: O Pensador das Diásporas.

5 Expressões retiradas de texto produzido por Glenn Jordan, da University of South Wales, UK, sobre Stuart Hall, a propósito de seu falecimento. Ver Jordan (2014).

6 Idem.

7 Tradução realizada por Tomaz Tadeu da Silva e Guacira Lopes Louro de um dos capítulos do livro Modernity and its Futures, organizado por HALL; HELD; McGREW (cf. ref. bibliog.). A primeira edição data de 1997, pela DP\&a Editora, do Rio de Janeiro. Com grande aceitação do público acadêmico, em diversas áreas do conhecimento, em 2006 o pequeno livro de pouco mais de cem páginas encontrava-se em sua $11^{\mathrm{a}}$ edição.

8 Tradução de Ricardo Uebel, Maria Isabel Bujes e Marisa Vorraber Costa do $5^{\circ}$ capítulo do livro editado por Kenneth Thompson, intitulado Media and Cultural Regulation (cf. ref. bibliog.). A versão em português foi publicada na revista Educação \& Realidade, da Faculdade de Educação da UFRGS (cf. ref. bibliog.).

9 Moreira considera que, ao lado das significativas contribuições trazidas aos estudos de currículo pela "onda culturalista", dela decorreram alguns problemas para tais investigações, que dizem respeito, especialmente, ao esmaecimento de algumas especificidades das questões curriculares pela transposição direta 
de categorias empregadas no estudo da cultura mais ampla para o âmbito do currículo, disso decorrendo o afastamento das teorizações daquilo que se pensa e diz nas escolas; à abertura de espaço à fragmentação, bem como a recortes investigativos muito limitados, ou à incorporação de temáticas cujas relações com o processo curricular não se mostram evidentes e, por fim, a um certo negligenciamento dos aspectos econômicos e políticos presentes no processo de escolarização, bem como das discussões, a seu ver extremamente necessárias, acerca do conhecimento a ser ensinado nas escolas e nas salas de aula.

10 Nossos agradecimentos aos professores-pesquisadores e professoras-pesquisadoras pelo acolhimento imediato ao nosso pedido e por abrirem espaço em suas agendas plenas de afazeres profissionais para elaborarem com presteza um texto com seus depoimentos particulares sobre a importância de Hall para a formulação/problematização/análise de questões relativas à educação no contexto acadêmico brasileiro.

\section{Referências}

ALIZART, Mark. Préface. In: ALIZART, Mark; HALL, Stuart; MACÈ, Éric; MAIGRET, Éric. Stuart Hall. Paris: Éditions Amsterdam, 2007. P. 9-11.

ALIZART, Mark; HALL, Stuart; MACÈ, Éric; MAIGRET, Éric. Stuart Hall. Paris: Éditions Amsterdam, 2007.

BUTLER, Patrick. Britânicos recordam Stuart Hall, 'pai do multiculturalismo'. Folha de São Paulo, São Paulo, p. A14, 14 fev. 2014.

DU GAY, Paul (Org.). Doing Cultural Studies: the story of the Sony Walkman. London: Sage; Open University 1997.

ESCOSTEGUY, Ana Carolina D. Stuart Hall: um esboço de um itinerário biointelectual. Revista Famecos, Porto Alegre, n. 21, p. 61-74, ago. 2003.

HALL, Stuart. Identidades Culturais na Pós-Modernidade. Tradução de Tomaz Tadeu da Silva; Guacira Lopes Louro. 11. ed. Rio de Janeiro: DP\&A, 2006.

HALL, Stuart. The Question of Cultural Identity. In: HALL, Stuart; HELD, David; McGREW, T. Modernity and its Futures. Polity Press/Open University Press, 1992. P. 273-316.

HALL, Stuart. The Centrality of Culture: notes on the cultural revolutions of our time. In: THOMPSON, Kenneth (Org.). Media and Cultural Regulation. London: Thousand Oaks, New Delhi: The Open University; SAGE Publications, 1997. P. 207-238.

HALL, Stuart. A Centralidade da Cultura: notas sobre as revoluções culturais do nosso tempo. Educação \& Realidade, Porto Alegre, v. 22, n. 2, jul./dez. 1997.

HALL, Stuart. O Pensador das Diásporas. Entrevista com Stuart Hall. Portal Literal. 2003. Disponível em: <http://www.literal.com.br/acervodoportal/o-pensador-das-diasporas-1105/>. Acesso em: 10 mar. 2014.

JORDAN, Glenn. On Stuart Hall: an engaged politics of humility. Cardiff School of Creative \& Cultural Industries, University of South Wales, UK, 2014 (texto digitado).

KUAN-HSING CHEN. A Formação de um Intelectual Diaspórico: uma entrevista com Stuart Hall. In: SOVIK, Liv (Org.). Da Diáspora. Identidades e mediações culturais. Belo Horizonte/Brasília: Editora da UFMG/ UNESCO, 2003. P. 407434 .

MORLEY, David; CHEN, Kuan-Hsing (Org.). Stuart Hall. Critical dialogues in Cultural Studies. London/New York: Routledge, 1996. 
RESTREPO, Eduardo; WALSH, Catherine; VICH, Victor (Org.). Sin Garantías: trayectorias y problemáticas en estudios culturales. Popayán/Lima/Bogotá: Instituto de Estudios sociales y Culturales Pensar/Instituto de Estudios Peruanos/Universidad Andina Simón Bolivar, 2010.

ROJEK, Chris. Stuart Hall. Cornualha: Polity Press/Blackwell, 2003.

SOVIK, Liv (Org.). Da Diáspora. Identidades e mediações culturais. Stuart Hall. Belo Horizonte/Brasília: Editora da UFMG/ UNESCO, 2003.

SOVIK, Liv. Stuart Hall: a favor da diferença. O Globo, Rio de Janeiro, 22 fev. 2014, s. p. 2014.

\section{Depoimentos citados}

AGUIAR, José Vicente de Souza. Depoimento Escrito. 2014. Manaus/AM, UEA. BONIN, Iara. Depoimento Escrito. 2014. Canoas/RS, ULBRA.

GUIMARÃES, Leandro Belinaso. Depoimento Escrito. 2014. Florianópolis/SC, UFSC.

MOMO, Mariangela. Depoimento Escrito. 2014. Natal/RN, UFRN.

MOREIRA, Antonio Flávio Barbosa. Depoimento Escrito. 2014. Petrópolis/RJ, UCP.

PARAÍSO, Marlucy Alves. Depoimento Escrito. 2014. Belo Horizonte/MG, UFMG. SANTOS, João de Deus dos. Depoimento Escrito. 2014. Cáceres/MT, UNEMAT.

Marisa Vorraber Costa é licenciada em Filosofia e doutora em Educação pela Universidade Federal do Rio Grande do Sul (UFRGS) com estágios de pós-doutorado em universidades de Portugal, Espanha e Alemanha. Professora Titular em Ensino e Currículo da UFRGS (aposentada), é Professora Adjunta no PPGEdu/ULBRA e docente convidada do PPGEdu/UFRGS. Foi pesquisadora do CNPq durante 15 anos e tem investigado as conexões entre cultura e pedagogia.

E-mail: vorrabercosta@gmail.com

Maria Lúcia Castagna Wortmann é doutora em Educação pela Universidade Federal do Rio Grande do Sul (UFRGS); Professora convidada do Programa de Pós-Graduação em Educação da Universidade Federal do Rio Grande do Sul (UFRGS) e Professora Adjunta no Programa de Pós-Graduação da Universidade Luterana do Brasil (ULBRA).

E-mail:wortmann@terra.com.br

Rosa Maria Hessel Silveira é professora titular aposentada da Faculdade de Educação da Universidade Federal do Rio Grande do Sul (UFRGS) e professora colaboradora permanente do PPGEdu da UFRGS, na linha "Estudos Culturais em Educação". Orienta trabalhos de mestrado e doutorado e organizou as obras "Estudos Culturais para professor@s" e "Cultura, poder e educação". É pesquisadora 1C do CNPq e atual coordenadora do NECCSO (Núcleo de Estudos Currículo, Cultura e Sociedade).

E-mail: rosamhs@terra.com.br 